\title{
Research on Modeling of Equipment Support Data Requirements Based on Activities
}

\author{
Jian Wang a), Ping $\mathrm{Gu}^{\text {b) }}$ \\ School of Army Engineering University, Shijiazhuang 050003, China; \\ a)wjdxslw@163.com, \\ b)1006691583@qq.com
}

\begin{abstract}
According to the characteristics of equipment support activities, this paper puts forward the idea of equipment support data requirements modeling, which is "activity-oriented and process-oriented". Firstly, the relationship between equipment support tasks, functions and activities is analyzed. Based on this, the model of equipment support activities is established, and the equipment support activities are recognized through the relation matrix between tasks, functions and activities. Then, the fuzzy comprehensive evaluation method is used to construct the evaluation model of activities. Finally, IDEF0 method is used to model the equipment support activities and extract the data requirements.
\end{abstract}

Key words: equipment support, data requirements, activity model, fuzzy comprehensive evalua- tion, IDEF0.

\section{INTRODUCTION}

With the advent of "big data" era, the equipment support data has been characterized by explosive growth and massive accumulation, which putting forward higher requirements on the equipment support data resources construction [1-3]. Data requirements analysis is the premise and foundation of the follow-up design work of data resources construction. It is very urgent to adopt an appropriate method to extract and integrate the equipment support data requirements. Through in-depth analysis of equipment support activities, we can find that these activities are essentially operated on personnel, material and information resources under the guidance of equipment support tasks. In other words, the operations, which are applied to personnel, material and information resources, depend on the equipment support tasks. So the equipment support activities have a certain degree of stability. Therefore, based on the stability factor of activity, this paper adopts the idea of "activity-oriented and processoriented" to extract and integrate the data requirements.

\section{THE IDENTIFICATION OF EQUIPMENT SUPPORT ACTIVITIES}

At present, the commonly methods used to recognize activities include business system planning method, enterprise functional decomposition method, etc. Each of these methods has its drawbacks. Such as the decomposition is rough, the operation process is arbitrary, or the analysis process is complex, etc. In order to overcome the shortcomings of the above methods, we need to find a new way to identify equipment support activities. By analyzing the characteristics of equipment support activities, this paper starts from the perspective of equipment support nodes performing the equipment support tasks and fulfilling the equipment support functions to determine the equipment support activities. 


\section{The Relationship between Equipment Support Tasks, Functions and Activities.}

The equipment support activities are determined by equipment support functions. But completing different equipment support tasks will use different equipment support functions and perform different equipment support activities. Through the implementation of equipment support activities, the equipment supports nodes with equipment support functions complete its equipment support tasks [4].

\section{The Model of Equipment Support Activities.}

By analyzing the relationship between equipment support tasks, functions and activities, it can be seen that the activities performed by equipment nodes are jointly decided by the functions and the tasks and can be expressed by functional relationships. For the sake of expression, the following symbols are introduced.

$\mathrm{N}$ : equipment support node;

E: equipment support element constituting equipment support node;

$\mathrm{T}$ : equipment support task of equipment support node;

t: sub-task obtained after equipment support node task decomposition;

F: equipment support function of equipment support node;

f: sub-function obtained after equipment support node function decomposition;

A: equipment support activities carried out by equipment support nodes;

a: equipment support activities corresponding to sub-tasks and sub-functions of the nodes;

$\mathrm{G}$ : the mapping from the tasks and functions to activities.

Therefore, the functional relationships between the equipment support tasks, functions and activities can be represented as:

$$
\begin{gathered}
\mathrm{A}=\mathrm{G}(\mathrm{T}, \mathrm{F}) \\
\mathrm{a}=\mathrm{G}(\mathrm{t}, \mathrm{f}) \mathrm{t} \subseteq \mathrm{T}, \mathrm{f} \subseteq \mathrm{F}
\end{gathered}
$$

After analysis, a is a subset of the activity set $\mathrm{A}$, that is $\mathrm{a} \subseteq \mathrm{A}$.

\section{The Relationship Matrix between Tasks, Functions and Activities.}

Equipment support task $\mathrm{T}$ can be decomposed into a number of relatively independent sub-tasks, such as $\mathrm{t}_{1}, \mathrm{t}_{2}$ and so on. The equipment support node $\mathrm{N}$ are consisted of several equipment support elements, such as $\mathrm{E}_{1}$ and $\mathrm{E}_{2}$ and so on. Each of the equipment support elements has certain functions. For example, the equipment support element $E_{1}$ has the functions $\mathrm{f}\left(\mathrm{E}_{1}\right)_{1}, \mathrm{f}\left(\mathrm{E}_{1}\right)_{2}$ and so on. In addition, the equipment support node is an organic whole composed by equipment support elements. According to the principle of system emergent, the overall functions of equipment support node are greater than all its components and functions and have new features, such as $\mathrm{f}(\mathrm{N})_{1}, \mathrm{f}(\mathrm{N})_{2}$ and so on. Therefore, the relationship between equipment support tasks, functions and activities can be expressed in a matrix form, which is shown in Table 1.

By using equation (2), each equipment support activity can be identified, such as $a_{111}=G\left(t_{1}, f\left(E_{1}\right)_{1}\right)$. Thus all activities of the equipment support node can be obtained. 
TABLE 1. The Relationship Matrix Between Tasks, Functions and Activities

\begin{tabular}{|c|c|c|c|c|c|}
\hline \multicolumn{2}{|c|}{ Task } & \multicolumn{4}{|c|}{$\mathrm{T}$} \\
\hline & Function & $\mathrm{t}_{1}$ & $\mathrm{t}_{2}$ & $\ldots$ & $t_{n}$ \\
\hline \multirow{4}{*}{$\mathrm{E}_{1}$} & $\mathrm{f}\left(\mathrm{E}_{1}\right)_{1}$ & $\mathrm{a}_{111}$ & $\mathrm{a}_{112}$ & $\ldots$ & $a_{11 n}$ \\
\hline & $\mathrm{f}\left(\mathrm{E}_{1}\right)_{2}$ & $\mathrm{a}_{121}$ & $a_{122}$ & $\ldots$ & $a_{12 n}$ \\
\hline & $\ldots$ & $\ldots$ & $\ldots$ & $\ldots$ & $\ldots$ \\
\hline & $\mathrm{f}\left(\mathrm{E}_{1}\right)_{\mathrm{n}}$ & $\mathrm{a}_{\ln 1}$ & $\mathrm{a}_{\ln 2}$ & $\ldots$ & $\mathrm{a}_{1 \mathrm{nn}}$ \\
\hline \multirow{4}{*}{$\mathrm{E}_{2}$} & $\mathrm{f}\left(\mathrm{E}_{2}\right)_{1}$ & $\mathrm{a}_{211}$ & $a_{212}$ & $\ldots$ & $a_{21 n}$ \\
\hline & $\mathrm{f}\left(\mathrm{E}_{2}\right)_{2}$ & $\mathrm{a}_{221}$ & $a_{222}$ & $\ldots$ & $a_{22 n}$ \\
\hline & $\ldots$ & $\ldots$ & $\ldots$ & $\cdots$ & $\ldots$ \\
\hline & $\mathrm{f}\left(\mathrm{E}_{2}\right)_{\mathrm{n}}$ & $\mathrm{a}_{2 \mathrm{n} 1}$ & $a_{2 n 2}$ & $\ldots$ & $a_{2 n n}$ \\
\hline$\cdots$ & $\ldots$ & $\ldots$ & $\ldots$ & $\ldots$ & $\ldots$ \\
\hline \multirow{4}{*}{$\mathrm{N}$} & $\mathrm{f}(\mathrm{N})_{1}$ & $\mathrm{a}_{11}$ & $\mathrm{a}_{12}$ & $\ldots$ & $\mathrm{a}_{1 \mathrm{n}}$ \\
\hline & $\mathrm{f}(\mathrm{N})_{2}$ & $\mathrm{a}_{21}$ & $\mathrm{a}_{22}$ & $\ldots$ & $\mathrm{a}_{2 \mathrm{n}}$ \\
\hline & $\ldots$ & $\ldots$ & $\ldots$ & $\ldots$ & $\ldots$ \\
\hline & $\mathrm{f}(\mathrm{N})_{\mathrm{n}}$ & $a_{n 1}$ & $a_{n 2}$ & $\ldots$ & $a_{n n}$ \\
\hline
\end{tabular}

\section{THE EVALUATION MODEL OF EQUIPMENT SUPPORT ACTIVITIES}

After confirming the specific activities through the relationship matrix between equipment support tasks, functions and activities, the comprehensiveness and rationality of the activities obtained need to be further evaluated,thus to lay a good foundation for the next data requirements analysis. By analyzing the characteristics and rules of equipment support, it is found that the equipment support activities are affected by many factors. The objective of evaluation is a fuzzy set composed of many factors, so the fuzzy comprehensive evaluation method is adopted [5]. The specific steps are as follows:

(1) Select the set of factors and comments of equipment support activities evaluation.

Here, define the set of factors $\mathrm{P}$ as: $\mathrm{P}=\left\{\mathrm{p}_{1}, \mathrm{p}_{2}, \ldots, \mathrm{p}_{\mathrm{m}}\right\}, \mathrm{p}_{1}, \mathrm{p}_{2}, \ldots, \mathrm{p}_{\mathrm{m}}$ are all the factors that reflect the characteristics of the equipment support activities. Define the set of comments $\mathrm{Q}$ as: $\mathrm{Q}=\left\{\mathrm{q}_{1}, \mathrm{q}_{2}, \ldots, \mathrm{q}_{\mathrm{n}}\right\}, \mathrm{q}_{1}, \mathrm{q}_{2}, \ldots, \mathrm{q}_{\mathrm{n}}$ are the comments rating of the equipment support activities.h

(2) Evaluate single factor.

In the process of single factor evaluation, the method of membership function is used to determine the membership degree of each factor in the comments set. Assuming that when the $i$-th factor $p_{i}(i=1,2, \ldots, m)$ in the set of factors $P$ is being evaluated, the membership degree of factor $p_{i}$ in the the $j$-th comment $q_{j}(j=1,2, \ldots, n)$ is $r_{i j}$. So the fuzzy set $U_{i}$ which evaluate the factor $p_{i}$ can be expressed as: $U_{i}=\left\{r_{i 1}, r_{i 2}, \ldots, r_{i n}\right\}$.

In this way, the evaluation set of $\mathrm{m}$ factors can form the evaluation matrix $\mathrm{U}$.

$$
U=\left(\begin{array}{c}
U_{1} \\
U_{2} \\
\vdots \\
U_{m}
\end{array}\right)=\left(\begin{array}{cccc}
r_{11} & r_{12} & \cdots & r_{1 n} \\
r_{21} & r_{22} & \cdots & r_{2 n} \\
\vdots & \vdots & & \vdots \\
r_{m 1} & r_{m 2} & \cdots & r_{m n}
\end{array}\right)
$$

(3) Establish the weight set of each factor.

Under normal circumstances, the importance of each factor is not the same. To reflect the impact of different factors, all factors need to be given a corresponding weight coefficient $\mathrm{w}_{\mathrm{i}}$. In this way, the set of all weight coefficients is called the weight set of factors and denoted by $\mathrm{W}$.

(4) Comprehensive evaluation.

$$
W=\left(\begin{array}{llll}
w_{1} & w_{2} & \cdots & w_{m}
\end{array}\right)
$$

Judging from the evaluation matrix of $m$ factors, the $i$-th row of $U$ reflects the membership degree of the i-th factor to each comment set, and the $\mathrm{j}$-th column of $U$ reflects the membership degree of all factors to the $j$-th 
comment. Therefore, when the evaluation matrix $\mathrm{U}$ and the weight set $\mathrm{W}$ are known, a matrix product operation can be performed on them to make a comprehensive evaluation.

$$
V=W \cdot U=\left(\begin{array}{llll}
w_{1} & w_{2} & \cdots & w_{m}
\end{array}\right) \cdot\left(\begin{array}{cccc}
r_{11} & r_{12} & \cdots & r_{1 n} \\
r_{21} & r_{22} & \cdots & r_{2 n} \\
\vdots & \vdots & & \vdots \\
r_{m 1} & r_{m 2} & \cdots & r_{m n}
\end{array}\right)=\left(\begin{array}{llll}
v_{1} & v_{2} & \cdots & v_{n}
\end{array}\right)
$$

In the formula above, $V$ represents the fuzzy comprehensive evaluation set, $v_{j}(j=1,2, \ldots, n$ )represents the membership degree of the judgment object to the $\mathrm{j}$-th comment when all the factors are considered.

\section{EQUIPMENT SUPPORT DATA REQUIREMENT MODELING}

After comparing and analyzing several typical modeling methods, such as CIMOSA, IDEF, UML and Petri net, it can be found that IDEF0 is a static process description model, which can express the system activity, data flow and the relationship between them at the same time [6]. Therefore, based on analyzing and confirming the equipment support activities, the IDEF0 method can be used to model the equipment support activities and extract the data requirements of equipment support. The specific steps are shown in Fig.1.

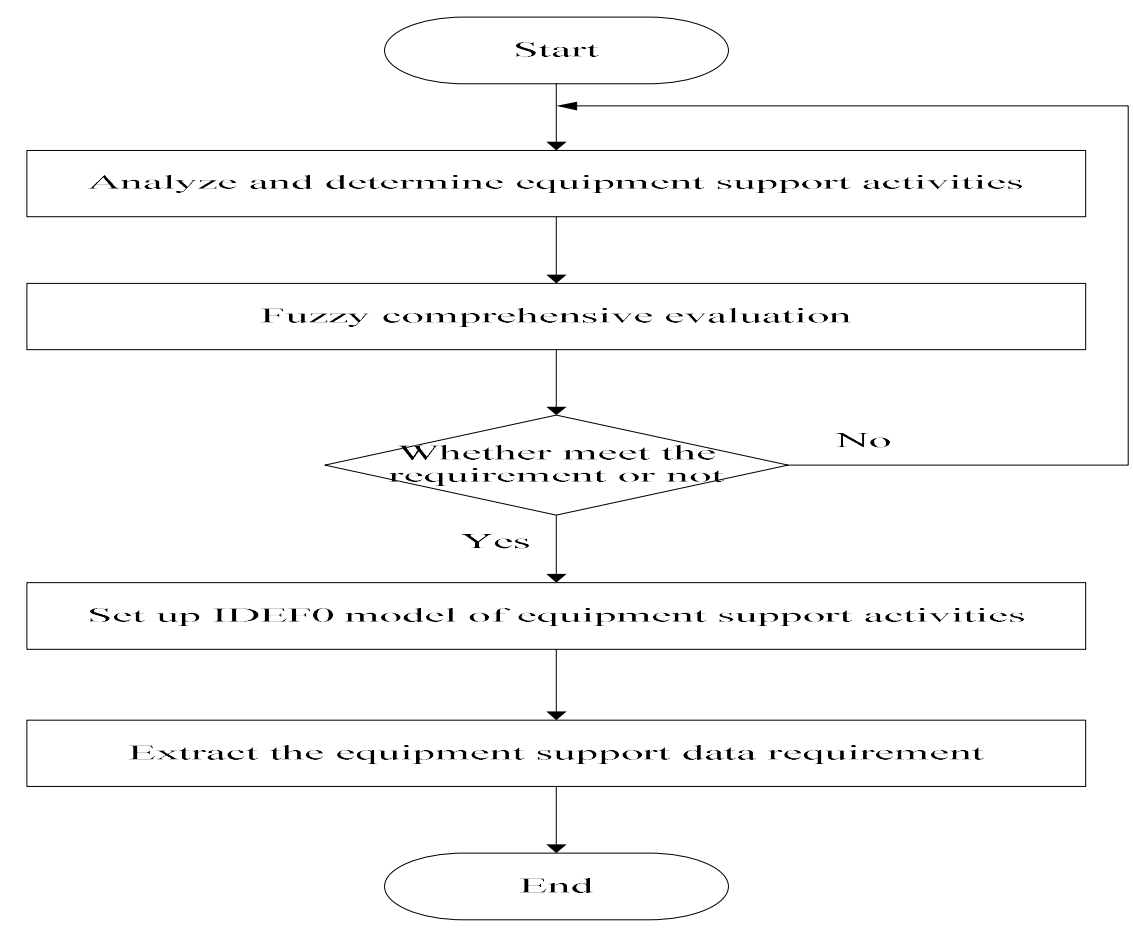

Fig.1 The modeling steps of equipment support data requirements

\section{SUMMARY}

Equipment support data requirements analysis is a very complex task, it makes sense to use a suitable method to obtain stable data requirements. Through analysis and research, it is found that the equipment supports activities do not depend on the instability factors such as organizational structure, operation flow and operation mode, etc. Therefore, this paper puts forward the idea of equipment support data requirements analysis based on activities, which has a certain theoretical and practical significance. 


\section{REFERENCES}

1. Liu Jianguo, Liu Shanyang, Liu Yaopeng, et al. Security requirements analysis method and its application [J]. Fire control and command control. Vol. 38 (2013) No. 6, p. 133-138.

2. Zhao Zhanliang, Gong Chuanxin, Feng Limin. Requirements analysis of military information system based on business description [J]. Journal of naval aviation engineering. Vol. 22 (2007) No. 3, p. 393-397.

3. Zhao Zhanliang, Gong Chuanxin. Problems and countermeasures in the requirements analysis of equipment support information system [J]. Computer engineering and designing. Vol. 28 (2007) No. 17, p. 4082-4085.

4. Li Zhishun. A course on military equipment support[M]. Beijing: military science press, 2012, p.1-13.

5. Shi Quan, Wang Lixin, Shi Xianming, et al. Decision and modeling of system [M]. Beijing: national defense industry press, 2016, p.123-129.

6. Cheol-Han Kim, Weston R H, Hodgson A, et al.The complementary use of IDEF and UML modeling approaches [J]. Computers in Industry. Vol. 24 (2003) No. 16, p. 35-56. 